\title{
ESP language teaching: a key to development in Guanacaste The English Teaching Case in the Tourist Major of the Universidad Nacional, Chorotega Regional Branch
}

\section{Ed. Lucía Svetlana Villanueva Monge}

The Tourist Industry has had a great development in the last ten tears in Costa Rica. This country has many special attractive destinations for foreigners that surpass a million and a half annually. The province of Guanacaste, one of the biggest and more visited of the country, is the perfect sample to illustrate the "Tourist Boom" inhabitants are experimenting today. Because of the multiple impacts the tourist industry has in different settings, but especially in the economy of the province, there is a need to prepare people better, day by day, to work in the industry, satisfying its high standards of quality. One of these requirements is the full command of the English language.

Today, the globalized world demands more people that have not only experience and the best academic formation 
to work in the industries, but also the ability to communicate in English. This aspect can make the difference in having better job positions or obtaining scholarships to study abroad. Thus, it is difficult to deny the relevance English has taken in the professional performance, but especially in Tourism.

Consequently, there is a need in Guanacaste to provide a good English instruction. Therefore, several educational institutions have tried to offer it, and one of these institutions is the Universidad Nacional (UNA) in its Chorotega Regional Branch campus in Liberia and Nicoya, which offers the major of Tourism with a bilingual component. Although there have been many efforts to improve the English teaching in the Tourist major of this university, these intentions have not been the most effective ones because of the presence of several difficulties such as the insufficient hours of the language instruction, the lack of courses with contents in which students can feel totally identified with the learning, and the few opportunities they have to practice the language in meaningful contexts and with foreign tourists. As a result, based on my experience as an English teacher of this major, it is essential to reestablish the English teaching in the Tourist major of the UNA with helpful strategies based on an English integrated instruction developed with specific purposes approach (ESP) that will lead to the practice of systematic activities like field trips and other accompanying. This will contribute to end with the real participation of these students as future successful professionals of the tourist industry, bringing benefits not only for themselves, but also for the community of Guanacaste.

For a better understanding of this proposal, it is necessary to make a reference of the problems related to this topic present not only in Guanacaste, but also in the major 
of tourism at UNA, to finally group the possible solutions with the corresponding recommendations.

The Guanacaste province is a region that represents $20 \%$ of the total national territory, with $8.2 \%$ of the national population. The Nation Status Report of Costa Rica describes how Guanacaste, in just 50 years, has turned its economy from an agricultural activity into a service one, especially related to tourism. At the same time, this province presents several characteristics that can be considered very competitive in terms of economy. For instance, it is the province with more tourist services declared by the Costa Rican Tourist Bureau, (ICT), counting with a lot of tourist mega - investments like the Papagayo Gulf project. Also, it has an international airport (Daniel Oduber Quirós Airport), with daily national and international flights, which transport thousand of tourists every week. The most recent infrastructure in Guanacaste was the creation of the Tempisque River Bridge that represents an important and faster means of communication between the cities of Nicoya and Santa Cruz and the capital of San José, in the Central Valley.

Concerning nature, Guanacaste has an important conservationist area called in Spanish "Area de Conservación Guanacaste", which was declared by UNESCO Patrimony of the Humanity. This component together with the strong cultural identity of its people exemplified with their sense of "Guanacastequidad" and its uncountable natural beauties like beaches and volcanoes make of Guanacaste a strong attraction for many of its visitors.

Although Guanacaste represents an important tourist zone to Costa Rica, paradoxically, it also represents the second region with a higher percentage of poverty in the whole country. According to the National Institute of Statistics and Census (INEC), it has the highest percentage of 
homes with extreme poverty with $13.7 \%$. That is why the government, in the last National Development Plan, has expressed its concern about this problem and proposed the need of enlarging the employment offer with tourist investments which may have a positive social effect. Here, it is more than clear the need of preparing people with a good English proficiency, among other requirements, to help them be an active part of the Guanacaste tourist labor market, which already has high standards of quality.

Therefore, it is important to improve the language teaching in the province; due to the urgency most of the people have to speak the language. This fact represents a particular challenge because it requires a turn in the traditional teaching of the language to a more focused one in the reality of the students and their professions.

As it was mentioned before, the UNA in its Chorotega Branch in Guanacaste, has offered the major of Tourism since 1999, forming professionals in this area. In the last two years, this major has become one of the most demanding in this regional branch with more than one hundred students, coming from different parts of the country. Several disciplines such as administration, biology, geography, sociology, informatics, and foreign languages like English and French compose its curricular design. In this last aspect, students are supposed to show an advanced proficiency level of English when they have fully completed the program. However, the reality is not even close to what these goals look for.

The undergraduate students' opinion, the situation of the graduated students in the labor market, and my own experience as an English teacher, tell that these learners, at the end of the program, are not able to have a full command of English. This problem has provoked that many graduates are not satisfied with their English formation. This 
fact is confirmed in the last report of the tourist major elaborated by authorities of the UNA Chorotega Regional Branch in 2005. Students complain about their competitive disadvantage related to the full command of English that most companies from the tourist industry in Guanacaste are asking for. These companies are looking for people who can have a real interaction with the tourists in English. This is a strong reason to hire people, no matter if they have an academic formation in college, or even if it is a specialization in tourist business.

This panorama is especially hard if we consider the students' high expectations after four years of studying this major in college. More disappointing for them is to know that, in many cases, they have been displaced by bilingual people that are coming from other countries or other areas of Costa Rica such as the Central Valley with no academic formation in tourism or any related field. Due to these facts, many graduates are forced to work in other settings different from the ones offered in the tourist industry, or are pushed to pay English courses in private institutions. In the worst cases, some students start all over again with a new major. Unfortunately, this goes against the general purposes of the UNA in forming bilingual entrepreneur professionals in the tourist industry.

In fact, this is a difficult goal to achieve if we take into consideration that students receive just four hours of instruction per week during the first six of the eight cycles that the major lasts. This is the same time students receive for any other academic course of the major. This time is insufficient to develop activities that promote in the students more quality in their participation, and better exposition to the target language.

Besides this time limitation, there is a lack of integrating objectives that link the English language and the 
academic content. In other words, there are no specifications in the course outline to teach the foreign language in context, related, in one way or another, to the tourist issues and activities, obviating the interest it can promote in students learning process.

In this sense, I had an experience with one of the beginner students' group with which I first realized about this problem. Following the bibliography suggested in the course descriptor, students started to use several textbooks in which their topics and activities were based on the life as immigrant in the United States. These textbooks have, as a main purpose, to work with students that are studying English as a second language in that country. It is not difficult to predict my students' reaction: they were really bored and confused because the topics were not part of their concerns. That was my starting point for trying to design courses directly connected to the reality of my students.

Other problem is the lack of opportunities students have to practice English with tourists or foreigners to get specific tasks done. In other words, the practical dimension of the language learning is limited to the classroom, with the teacher and the classmates. That aspect, even though is a very good way to practice the language, it is not as sufficient and rich as the one presented with tourists. Likewise, there are many students in the major that hardly ever have a conversation with the foreign tourists.

All the previous leads to the idea of providing activities that can contribute to change the problems presented before. This implies the need to introduce a new integrated English instruction based on the following actions.

First, it is necessary to increase the English instructional hours from four to twelve per week. In this way, students will have the opportunity to pursuit activities not only during the classes, but also at home with the fulfillment of 
different tasks required as projects or special homework. Teacher and students can track down these goals, by the constant checking of the results and, of course, the frequent practice of the language.

Second, it is significant to implement an English language teaching based on the English for Specific Purposes (ESP) approach that, at the same time, is eclectic in the use of several methodologies because they are chosen according to the needs of the students. This last aspect is what the ESP approach looks for. In other words, the fundamentals of this approach are focused in designing courses to meet learner's needs. In the case of the tourist major students, the English curriculum must be integrated with academic contents. The target language is a vehicle to learn or reinforce contents related to the tourism that are students' concern. Then this approach is not taught as a subject separated from the students' real world and possible professional settings. On the contrary, it is integrated into a subject matter area important for the students.

The benefits of this kind of teaching is mainly, its capacity to appeal the attention of the students, making the classes interesting for them while they are practicing the language. Then the students' motivation plays an essential role in their learning process. This works in every learning process but especially when it is presented with interesting familiar topics.

Definitely, a content-based English instruction is more attractive to many students than language classes that focus on language alone and are not challenging for the academic point of view. For instance, in the tourist English classroom, students will learn about specific subject matter content in English with topics like travel agencies, hotels, restaurants, tour operator agencies, cruises, tourist information services, guiding speaking, airport speaking, leisure 
activities, ecologic and nature attractions, culture, and many more. Students can explain processes, for example, by preparing cocktails and special recipes in the class using the target language. This is a funny activity that will be difficult to forget for the students. Also, a lesson can be planned to have discussions about tourist project implementations, and strategies to lead the tourism industry to what the province needs for its development.

As I said before ESP can use different methodologies. In this case, the communicative learning is one of them. The communicative competence, which focuses more in the functions instead of the form of the language, enables students to communicate effectively. The priority of the tourist major students must be that, to understand and speak the language to have real communication. In this sense, ESP has the advantage from other language teaching related to the objectives of the instruction. Thus, ESP focuses in the development of the four skills of the language as listening, reading, writing and speaking; but needs to concentrate more on the speaking skill that is primary important to the well performance of the future professionals.

Third and last, it is necessary to implement systematic and innovated outdoor activities based on the Project Base Learning methodology, in which students will use English as a tool to get important information established as a goal. Here, students are called to work together, as a team, for doing specific projects during field trips, short practices, and other accompanying, with the objective to look for answers that are part of their own concern and relevant to investigate. This takes them to the practice of another methodology, which is the cooperative learning. The professor is not the only person who has the information required. Students can get information from their own classmates or people that are part of the tourist industry. In fact, 
while cooperative learning improves group achievement, it is particularly helpful for low achieving students. This makes its application significant.

These outdoor activities are the complement of the indoor ones, which together, can consolidate the knowledge presented in the class. The practice of the target language in real contexts with different tourist settings will help students to develop, naturally, their speaking skills. Of course, the activities proposed need to be systematically organized in an integrated way with specific objectives to each of the subject matter contents. For instance, students can practice their oral English skills with the implementation of a project base learning associated to field trips that can involve interviews, surveys and other activities necessary to get the tasks done. For the success of these activities it is required a carefully coordination with other teachers from the different subjects in order to integrate the objectives. Just to mention an example, during a field trip to the Mid- Pacific of Costa Rica, an academic objective for the "Hotel Managing" course can be "to identify the perspectives of the tourist industry in the zone". The same can be combined with a communicative competence objective in the English course related to "request opinions about the quality of the attractions and tourist services in the area with its corresponding suggestions". Both purposes imply to do activities such as interviews with staff hotels, managers, and tourists, to finally establish comparisons and conclusions in the class, and by using all the technology students may have as a didactic resource.

This proposal requires several characteristics from the professor. Primarily, the teacher should plan their classes carefully and integrally with teachers from other subjects, using specific textbooks and materials that are part of the tourism major or especially designed for English tourist 
courses. Also, he /she is called to focus less in the product and more in the process, while increasing the learner's motivation by mastering language and at least, the basis of the subject matter. This teacher's competence is an essential ingredient to have a real communication through the students' learning process. The teacher is required to have an open mind and a positive attitude toward the ESP content, and do all the necessary arrangements in order for students to have meaningful experiences in every activity planned. In much the same, the professor is the one who helps students in their assessment and positive feedback, and is the one who has the best position to identify learners changing needs according to their own motivation and interests.

On the other hand, learners, that in this case are the tourist major students, must have an active role in their learning process. When they go out of the class to settings beyond their own control, talking with tourists in English and investigating at the same time, they are taking risks and are gamblers of their own learning process. All these actions help the learners to increase competence by learning language and content easily and faster in an enjoyable and satisfying way.

Precisely, I could check this feeling of satisfaction with my students last year when they had to interview tourists in different parts of Guanacaste to get a project done. The result of this experience surprised them when they proved they could do it with no major problems. They reduced their fear to talk or lower their affective filter, and realized that it was not difficult to communicate with foreign tourists if they were well prepared. Their self-confidence got stronger then.

In this sense, and as a recommendation, it is important to clarify that to apply these ESP strategies, students must have at least an intermediate proficiency level of the 
language, because, in other way, they will not be capable to understand and produce the language required.

Another recommendation is to establish alliances with tourist companies, which are willing to collaborate with the improvement of the tourism in Guanacaste. This idea can be possible by receiving, in their locations, the tourist major students to work as assistants in any service of the company. This aspect is vital to let students apply their knowledge and learn more about both, target language and subject matter content, and at the same time, cooperate with the service of the host company.

Also, it will be considered necessary for teachers and authorities to get together periodically to coordinate the integration of the courses' objectives and related activities such as the short practices and the field trips. This must be a team goal. The result of this interaction can be illustrated in nice and useful activities for both the English and the subject matter content teaching. Of course, this involves a great effort from all the parts, but especially a positive attitude to the changes that already require dedication and work.

A final suggestion is the use of technology in class for the presentation of the results of the different projects assigned or any other activity done in class. Related to this point, authorities from the UNA must facilitate the students multimedia resources in order for them to practice their knowledge in informatics, at the same time they present their conclusions in an appropriate way. Once again, the use of the language laboratory is obligatory to help learners be more exposed to the target language by listening and having conversational activities. These actions will let students be better prepared to manage any situation they can have in their possible encounters with foreigners in the professional tourist settings. 
In conclusion, this proposal of changing the English language teaching, is an initiative that was born on the feeling that we, English teachers, were not doing much to help the students to communicate in English effectively, being this aspect the main cause of their frustration and the reason to have many difficulties in finding a good position in the tourist labor market of Guanacaste. According to this panorama, it is crucial to implement meaningful English teaching such as the English for Specific Purposes approach, which turns learners into users of the language by giving them more and better instruction, integrating tourist content and language objectives, and promoting specific practical activities like the field trips and short practices.

The compensation for this implementation to teachers and authorities at UNA will be the key they are giving the students to open a branch of new and better opportunities in many settings, but especially in the economical one. The compensation for Guanacaste and for the country in general will be the takeoff to the real and expected development.

To continue working on this special kind of English teaching is a constant challenge for all the parts involved, but especially it is an opportunity to enhance the English teaching towards establishing strategies to help students experimenting the feeling of accomplishing the English language. 